\title{
Pensononowoor
}

2018, vol. 80, 48-60

http://dx.doi.org/10.12657/denbio.080.005

\author{
Quan Qiu, Junhui Wang, Yan Su, Jiyue Li*, Jianwei Ma, Qian $\mathrm{He}^{*}$
}

\section{Organ-level evaluation of the carbon starvation hypothesis in deciduous broad-leaved Catalpa bungei plants undergoing drought-induced mortality}

Received: 13 March 2018; Accepted: 3 August 2018

\begin{abstract}
The carbon starvation hypothesis $(\mathrm{CSH})$ is one of the current leading hypotheses regarding the mechanism of plant death, although it has not been sufficiently validated due to a lack of evidence. To help verify the role of carbon starvation in plant mortality, we measured the non-structural carbohydrate (NSC) concentration ([NSC]) in different organs (roots, stems, and leaves) of plants of Catlapa bungei clone 9-1 after the cessation of photosynthesis and death due to drought and in well-watered controls. Drought induced the loss of NSC reserves, which was observed in all organs at death, and carbon starvation appeared to begin after the cessation of photosynthesis. The [NSC] dynamics, occurrence time of carbon starvation, and survival time varied among the organs, and even within the same organs at different stem heights. Overall, our findings are compatible with the $\mathrm{CSH}$ in that carbon starvation occurs in roots, stems, and leaves and concurs with plant death during prolonged drought.
\end{abstract}

Keywords: Carbon starvation, Catalpa bungei, Drought, Non-structural carbohydrate (NSC), Plant mortality

Addresses: Q. Qiu, Y. Su, J. Li, Q. He, Guangdong Key Laboratory for Innovative Development and Utilization of Forest Plant Germplasm, College of Forestry and Landscape Architecture, South China Agricultural University, 510642, Guangzhou, People's Republic of China, e-mail: ljyue@scau.edu.cn, e-mail: heqian69@126.com

J. Wang, State Key Laboratory of Tree Genetics and Breeding, Key Laboratory of Tree Breeding and Cultivation of State Forestry Administration, Research Institute of Forestry, Chinese Academy of Forestry, Beijing 100091, People's Republic of China

J. Ma, Xiaolongshan Forestry Science and Technology Research Institute, 741022, Tianshui Gansu, People's Republic of China

*Corresponding authors

\section{Introduction}

Worldwide, massive tree mortality events have caused widespread public concern. These events may be associated with climate change-induced drought, and have been observed in a variety of forests in different geologic and climatic domains (Liang et al., 2003; Bréda et al., 2006; Adams et al., 2009; van 
Mantgem et al., 2009; Allen et al., 2010; Paddock et al., 2013; Niu et al., 2014; Pellizzari, 2016), including arid regions in China (Liang et al., 2003; Zhang et al., 2014). Compared to temperature, light, and palaeo- $\mathrm{CO}_{2}$ concentration variations, drought is the main climatic characteristic associated with tree mortality (Rebetez \& Dobbertin, 2004; Allen et al., 2010), but the mechanisms of drought-induced tree mortality remain unclarified (McDowell et al., 2008; Sala et al., 2010). The hydraulic failure hypotheses (HFH) and carbon starvation hypotheses (CSH) are the current leading hypotheses of the mechanism of plant death (McDowell, 2011). Numerous studies have tested these hypotheses at the organ (Hartmann et al., 2013; O'Grady et al. 2013; Salmon et al., 2015), individual (Sevanto et al., 2014; Wang et al., 2016), and forest (Rowland et al., 2015) levels; however, the results have been inconclusive. As summarized by Adams et al. (2017), recent research supports the notion that physiological mechanisms of drought-induced tree mortality may be explained by the two controversial statements: hydraulic failure inhibits water transport through the loss of xylem function from embolism, leading to tissue desiccation; and carbon starvation via imbalance between carbohydrate demand and supply may lead to an inability to meet osmotic, metabolic and defensive carbon requirements (Hartmann et al., 2013; Heres et al. 2014; Sevanto et al., 2014).

A growing number of empirical studies have suggested that hydraulic failure rather than carbon starvation determines plant mortality during drought (Vilagrosa et al., 2003; Hartmann et al., 2013; Sevanto et al., 2014; Pellizzari et al., 2016), and the latest results have revealed that hydraulic failure during drought-induced mortality is widespread across species, whereas carbon starvation is not universal (Adams et al., 2017). Moreover, Adams et al. (2017) noted that non-structural carbohydrate (NSC; mainly soluble sugars and starch) loss was more common in gymnosperms than in angiosperms and was connected to xylem hydraulic vulnerability. Similarly, numerous studies have shown that both hydraulic failure and carbon starvation induce tree mortality (Heres et al. 2014; Sevanto et al., 2014), and their interaction in dying trees has been observed (Salmon et al., 2015; Wang et al., 2016). Overall, the hydraulic failure hypothesis is well accepted, but the $\mathrm{CSH}$ remains controversial. Nonetheless, carbon starvation seems to be closely related to tree mortality due to its potential role in diminishing hydraulic function (Adams et al., 2017). Thus, loss of carbohydrate reserves should be experimentally observed and verified to better understand the mechanism of tree mortality. Carbon starvation occurs when carbon supplies from photosynthesis, mobilisation of NSCs, and autophagy (i.e., vacuolar proteolysis) are lower than the carbon required for respiration, growth, and defence (McDowell, 2011). Hence, plants succumb to drought when there are insufficient NSCs to support metabolism and regeneration (Sala et al., 2010). The $\mathrm{CSH}$ was formulated to explain tree mortality during long-term drought, but no direct evidence exists supporting its role in drought-induced mortality in trees (Ward et al., 2005; Gruber et al., 2012). Therefore, the validation and clarification of the mechanisms of carbon starvation warrant further discussion (McDowell \& Sevanto, 2010). In our opinion, to clarify the role of carbon starvation, NSC should be quantified in plants that are in the process of dying or have already died, as seen from some previous studies (Piper et al., 2009; McDowell et al., 2010; McDowell, 2011). In particular, the minimum NSCs required for the maintenance of metabolism and defence must be determined, and the threshold NSC concentration ([NSC]; per unit of dry matter (DW), $\mathrm{mg} \mathrm{g}^{-1} \mathrm{DW}$ ) should be quantified; furthermore, future research on carbon starvation should focus on these tipping points of mortality (McDowell, 2011). In recent years, numerous studies have focused on the NSC dynamics and the processes by which plants succumb to drought to examine the mechanism of carbon starvation on coniferous (Ward et al., 2005; Hartmann et al., 2013; Salmon et al., 2015) and evergreen (Piper, 2011) trees. More deciduous broad-leaved trees should be studied to test the NSC metabolism and carbon starvation mechanism, although some similar studies on deciduous broadleaved trees (e.g., Acer pseudoplatanus, Populus tremuloides ) have been reported (Anderegg et al., 2012; Piper \& Fajardo, 2016).

In addition, differential NSC allocation to plant organs should be studied during drought, as it seems to differ among tree species and may be related to distinct drought-resistance abilities and strategies, as well as drought stress duration and severity. For example, Barbaroux et al. (2003) detected differences in NSC reserves and responses to stress among organs in plants. Meanwhile, O'Grady et al. (2013) examined the roles of carbon and water dynamics in tree mortality in terms of "thirsty roots" and "hungry leaves". Similarly, in a preliminary experiment, we observed that stems and leaves at different stem heights had different survival times during long-term drought, and we speculated that this might be attributable to differences in NSC reserve allocation, carbon sequestration and translocation, or metabolic necessities among organs; however, this remains unclarified due to a lack of comprehensive data. Thus, considering the differential responses of NSC reserves in organs to drought stress, we aimed to further verify and clarify the CSH of plant mortality at the organ level to understand the mechanisms of carbon starvation.

Catalpa bungei, a deciduous broad-leaved tree that is native to China, has been planted widely in temperate regions of China. Large areas of $C$. bungei in 
north-western China experience climatic drought, and the exact mechanism of mortality is of great concern. Therefore, we studied the NSC dynamics and carbon starvation mechanisms associated with mortality in C. bungei. C. bungei plants were grown under two treatments, drought and a well-watered control, to determine the [NSC] during drought-induced mortality. Our objective was to identify the changes in NSC reserves at the organ level at two endpoints (zero net photosynthetic rate (Pn) and death) caused by drought and determine the difference in [NSC] dynamics among organs.

\section{Methods}

\section{Plant material and growth conditions}

One-year-old plants of $C$. bungei clone 9-1 were obtained from Luoyang City, Henan Province, People's Republic of China, and transplanted into flower pots in early March 2015. The flower pots measured $30 \mathrm{~cm}$ (top diameter) $\times 30 \mathrm{~cm}$ (bottom diameter) $\times 45 \mathrm{~cm}$ (height). Plastic pellets were placed in the flower pots under every plantlet to prevent water loss and soil erosion. The empty space was filled with potting soil. The soil field capacity and bulk density were measured using the core cutter method, and its chemical properties were determined following the methods described by $\mathrm{Lu}$ (1999). Table 1 presents the physical and chemical properties of the potting soil. The plants were planted and allowed to acclimate for 3 months in a plastic film greenhouse measuring $60.0 \mathrm{~m}$ (length) $\times 8.0 \mathrm{~m}$ (width) $\times 3.0 \mathrm{~m}$ (the height of the tunnel), arch space of $1.0 \mathrm{~m}$, and total area of $480.0 \mathrm{~m}^{2}$. During acclimation, plants were watered well daily and protected against insects and disease. The study site was located at the Xiaolongshan Forestry Science and Technology Research Institution, Tianshui, Gansu Province $\left(34^{\circ} 29^{\prime} \mathrm{N}, 105^{\circ} 48^{\prime} \mathrm{E}\right.$, $1160 \mathrm{~m}$ a.s.l.), which is in a temperate zone within a semi-humid monsoon climatic region. The average annual rainfall and evaporation capacity at the site are $600 \sim 800 \mathrm{~mm}$ and $1290 \mathrm{~mm}$, respectively. The average annual temperature is $11^{\circ} \mathrm{C}$, and the frostfree period lasts $\sim 180$ days. During the experiment, the daily average temperature in the greenhouse ranged from 20 to $38^{\circ} \mathrm{C}$, and daily average humidity was $40-65 \%$. Before treatment, the average stem height and basal diameter of the plants were $1.64 \mathrm{~m}$ and $12.81 \mathrm{~mm}$, respectively.

\section{Experimental design}

In a preliminary experiment, we observed that plants at stem death could not be revived and did not resprout with persistent rehydration (Table S1); thus, plant death was defined as stem death in the present study. We divided 90 plants into two treatments, a well-watered control (CK, 40 plants) and drought (D, 50 plants). CK plants were watered well throughout the experimental period, whereas water was withheld from D plants beginning on July 25, 2015 (mid-growing season in north-western China). $\mathrm{D}$ plants were divided into four groups: $\mathrm{D}$-model (n $=10)$, Start $(n=10)$, Zero-Pn $(n=10)$, Leaf death $(n=10)$, and Stem death $(n=10)$. CK plants were divided into three groups: CK-model $(n=10)$, CK1 $(n=10)$, CK2 $(n=10)$, and CK3 $(n=10)$. The stem height and basal diameter among the groups did not differ significantly $(P>0.05)$. The Start group included plants that were harvested before the drought treatment (i.e., at the start of the experiment), Zero-Pn was defined as the group in which photosynthesis has ceased (i.e., zero Pn), Leaf-death was defined as the group in which all the leaves of plants died due to drought, and Stem-death was defined as the group in which the stems of plants died due to drought (all $n \geq 5)$. CK1, CK2, and CK3 represented the respective controls versus Zero-Pn, Leaf death, and Stem death. Leaf-death was considered to have occurred once all leaves discoloured to orange and defoliation was apparent, and Fv/Fm (maximum quantum yield of PSII) values were used as a supplemental basis for the identification of leaf death. Stem-death was confirmed by staining stem samples with $0.1 \%$ neutral red after the stems changed from green to grey (Peterson, 1979). In D-model and CK-model plants, which were only used for observation rather than harvest sampling, the soil water content (SWC; i.e., water volume/soil volume) was measured every day using a handheld time domain reflectometer (FOM/ mts type; Easy Test, Ltd., Lublin, Poland). The Fv/Fm values of the fourth and fifth fully expanded leaves from the apex was measured using a portable chlorophyll fluorometer (MINI-PAM; Walz, Effeltrich, Germany). The instantaneous Pn in the fourth and fifth fully expanded leaves counting from the apex was determined at 9:00-10:30 h every day under constant light (photosynthetically active photon flux density: $1000 \mu \mathrm{mol} \mathrm{m}{ }^{-2} \mathrm{~s}^{-1}$ ) under ambient $\mathrm{CO}_{2}$ concentrations $(400 \mathrm{ppm})$ and leaf temperature $\left(30^{\circ} \mathrm{C}\right)$ (Li-6400; Li-Cor, Inc., Lincoln, NE, USA).

Table 1. Physical and chemical properties of the potting soil

\begin{tabular}{|c|c|c|c|c|c|c|c|c|c|}
\hline $\begin{array}{c}\mathrm{FC} \\
\text { (volume,\%) }\end{array}$ & $\begin{array}{l}\text { Bulk density } \\
\qquad\left(\mathrm{g} \mathrm{cm}^{-3}\right)\end{array}$ & $\mathrm{pH}$ & $\begin{array}{l}\text { Organic matter } \\
\qquad\left(\mathrm{g} \mathrm{kg}^{-1}\right)\end{array}$ & $\begin{array}{l}\text { Total N } \\
\left(\mathrm{g} \mathrm{kg}^{-1}\right)\end{array}$ & $\begin{array}{l}\text { Total P } \\
\left(\mathrm{g} \mathrm{kg}^{-1}\right)\end{array}$ & $\begin{array}{l}\text { Total K } \\
\left(\mathrm{g} \mathrm{kg}^{-1}\right)\end{array}$ & $\begin{array}{l}\text { Available N } \\
\left(\mathrm{mg} \mathrm{kg}^{-1}\right)\end{array}$ & $\begin{array}{l}\text { Available P } \\
\left(\mathrm{mg} \mathrm{kg}^{-1}\right)\end{array}$ & $\begin{array}{c}\text { Available K } \\
\left(\mathrm{mg} \mathrm{kg}^{-1}\right)\end{array}$ \\
\hline 31.95 & 1.04 & 6.86 & 64.70 & 2.30 & 0.80 & 18.14 & 178.94 & 25.46 & 179.08 \\
\hline
\end{tabular}

FC: field capacity; N: nitrogen; P: phosphorus; K: potassium. 


\section{Harvesting and sample preparation}

Based on the observations of the D-model and CK-model plants, four D plants harvests were performed. The first harvest (Start) was obtained at the start of the experiment. When plants were determined to have reached the Zero-Pn stage, the second harvest of CK1 and Zero-Pn plants was obtained. The third harvest (CK2 and Leaf death) followed the leaf death of the D plants. The fourth harvest (CK3 and Stem death) was obtained when stem death was confirmed. After harvesting, plants were divided into fine roots (diameter $\leq 2 \mathrm{~mm}$ ), coarse roots (diameter $>2 \mathrm{~mm}$ ), upper stems (upper half of the total stem height), lower stems (lower half of the total stem height), upper leaves (from the upper stem), and lower leaves (from the lower stem). The samples were prepared for the NSC analysis. After washing, the samples were oven-dried at $80^{\circ} \mathrm{C}$ for $72 \mathrm{~h}$, collected in numbered sample bags, crushed, and sieved through a 100-mesh screen. Since the leaves and stems at different stem heights of plants died asynchronously during the drought period based on the preliminary observations, in the present study, the upper and lower stem and leaf deaths were recorded separately. In addition, defoliation occurred as drought progressed; therefore, the fallen leaves were collected as leaf samples for the Leaf-death group; leaf samples were harvested only twice (Zero-Pn and Leaf death).

\section{NSC analysis}

In this study, NSC was defined as the sum of total soluble sugars (TSS) and starch. The TSS concentration ([TSS]) and starch concentration ([Starch]) were determined using the anthrone-sulphuric acid colourimetric method, as described by Zou (1995), and were expressed as $\mathrm{mg} \mathrm{g}^{-1} \mathrm{DW}$. Based on this definition of NSC, the [NSC] of roots, stems, and leaves was calculated as $[\mathrm{NSC}]=[\mathrm{TSS}]+[$ Starch $]$.

\section{Statistical analysis}

Data are expressed as the mean \pm standard deviation $(n=10)$. Figures were prepared using SigmaPlot ver. 10.0 (Systat, San Jose, CA, USA). Using SPSS ver. 20.0 (SPSS, Inc., Chicago, IL, USA), two-way analysis of variance (ANOVA) was applied to test the effects of the treatment and harvesting time, Tukey test was used to detect the differences among harvesting times within the same treatment, and the differences between the treatments at the same harvesting time were analysed using Student's t-test. $P<0.05$ was considered to indicate statistical significance.

\section{Results}

\section{Key physiological parameters analysis and morphological observations}

Under the well-watered condition, the SWC fluctuated within a narrow range $(36.2-40.4 \%)$, and the Pn (7.99-8.52 $\left.\mu \mathrm{mol} \mathrm{m}^{-2} \mathrm{~s}^{-1}\right)$ and Fv/Fm (0.76-0.84) of well-watered plants showed no changes during real-time observations (Fig. 1). Pn declined rapidly during the drought treatment, decreasing to 0 at 8 days after the start of the experiment (Fig. 1A). Meanwhile, Fv/Fm decreased gradually during the drought treatment, reaching $0.18 \pm 0.02$ at 16 days after the start of the experiment (Fig. 1B). During long-term drought, differences in the survival time among organs, as well as the stems and leaves at different stem heights, were observed (Fig. 1C). Specifically, stem and leaf survival time followed the order lower leaf < upper leaf < upper stem < lower stem, dying at $15,20,26$, and 34 days after the start of the experiment, respectively. In addition, the soil moisture supply (i.e., relative soil water content) decreased gradually over the course of the drought, and D plants showed different performance during the drought (Table 2). Based on the key parameters and observations during each harvesting time (Table 2), the four harvests were respectively conducted at 0 , 8,20 , and 34 days after the start of the experiment.

\section{The effects of treatment and harvesting time on NSC}

According to the two-way ANOVA results (Table $3)$, the organ [TSS] (except coarse root), [Starch], and [NSC] values generally differed significantly between treatments, and the plants at different harvesting times generally showed significant differences in organ [TSS], [Starch], and [NSC], although

Table 2. Key parameters and definitions of harvesting time

\begin{tabular}{ccccl}
\hline No. & Harvest group & Days after the start of the experiment (d) & RSWC (\% FC) & \multicolumn{1}{c}{ Key observations in plants } \\
\hline 1 & Start & 0 & 117.78 & Healthy; dark-green leaves; green stems \\
2 & Zero-Pn & 8 & 48.83 & Pn = 0; light-green curly leaves; green stems \\
3 & Leaf-death & 20 & 24.73 & All leaves died; defoliation; green stems \\
4 & Stem-death & 34 & 21.60 & All stems died; defoliation; grey stems \\
\hline
\end{tabular}

RSWC: relative soil water content, FC: field capacity. 


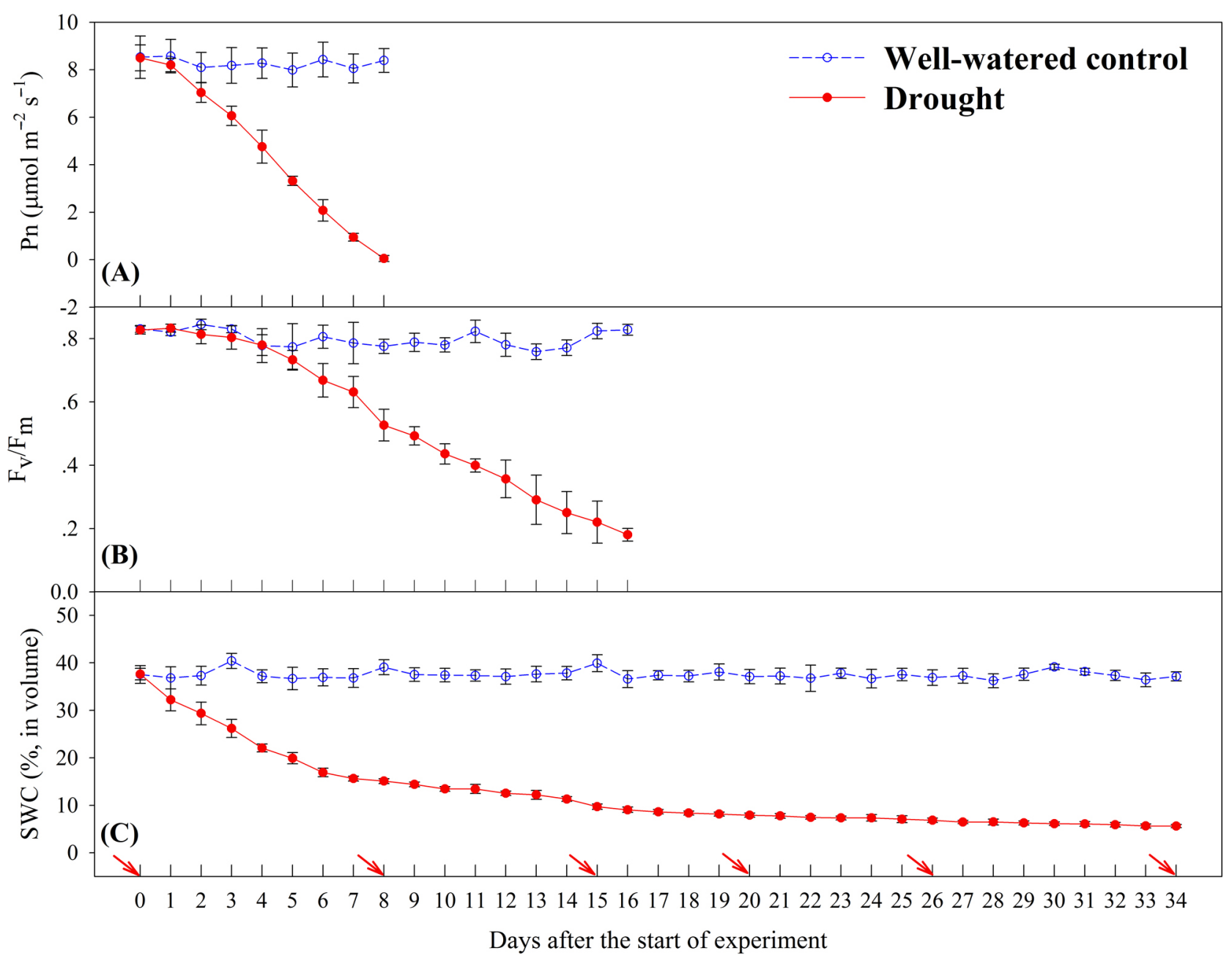

Fig. 1. Effects of treatment (drought and well-watered control) on the (A) instantaneous net photosynthetic rate (Pn), (B) $\mathrm{F}_{\mathrm{v}} / \mathrm{F}_{\mathrm{m}}$ in Catalpa bungei plants, and (C) soil water content (SWC). The arrows indicate key timepoints (0 d: start of experiment, first harvest; $8 \mathrm{~d}$ : $\mathrm{Pn}=0$, second harvest; $15 \mathrm{~d}$ : lower leaf death; $20 \mathrm{~d}$ : upper leaf death, third harvest; 26 $\mathrm{d}$ : upper stem death; $34 \mathrm{~d}$ : lower stem death). The values are the mean \pm standard deviation $(n=10)$

Table 3. Summary of the results of two-way ANOVA for the effect of treatment (drought vs. control) and harvesting time (Zero-Pn vs. Leaf death vs. Stem death) on concentrations of total soluble sugars (TSS) ([TSS]), starch ([Starch]), and non-structural carbohydrate (NSC) ([NSC]) in different organs. Note: leaf samples were only harvested twice (Zero-Pn and Leaf-death) due to defoliation

\begin{tabular}{|c|c|c|c|c|c|c|c|c|}
\hline \multirow{2}{*}{ Organ } & \multirow{2}{*}{ Effect } & \multirow{2}{*}{$\mathrm{df}$} & \multicolumn{2}{|c|}{ [TSS] } & \multicolumn{2}{|c|}{ [Starch] } & \multicolumn{2}{|c|}{$[\mathrm{NSC}]$} \\
\hline & & & $F$ ratio & $P$-value & $F$ ratio & $P$-value & $F$ ratio & $P$-value \\
\hline \multirow[t]{3}{*}{ Upper leaf } & Harvesting time & 1 & 0.001 & 0.970 & 10.254 & 0.003 & 0.675 & 0.417 \\
\hline & Treatment & 1 & 154.157 & $<0.001$ & 10.640 & 0.002 & 110.852 & $<0.001$ \\
\hline & Treatment $\times$ Harvesting time & 1 & 48.190 & $<0.001$ & 6.036 & 0.019 & 49.446 & $<0.001$ \\
\hline \multirow[t]{3}{*}{ Lower leaf } & Harvesting time & 1 & 5.936 & 0.020 & 0.188 & 0.667 & 6.919 & 0.012 \\
\hline & Treatment & 1 & 38.500 & $<0.001$ & 26.441 & $<0.001$ & 59.951 & $<0.001$ \\
\hline & Treatment $\times$ Harvesting time & 1 & 14.820 & $<0.001$ & 24.020 & $<0.001$ & 7.340 & 0.010 \\
\hline \multirow[t]{3}{*}{ Upper stem } & Harvesting time & 2 & 12.916 & $<0.001$ & 2.439 & 0.097 & 6.503 & 0.003 \\
\hline & Treatment & 1 & 103.233 & $<0.001$ & 32.818 & $<0.001$ & 126.080 & $<0.001$ \\
\hline & Treatment $\times$ Harvesting time & 2 & 44.856 & $<0.001$ & 7.158 & 0.002 & 7.857 & 0.001 \\
\hline \multirow[t]{3}{*}{ Lower stem } & Harvesting time & 2 & 8.237 & 0.001 & 8.049 & 0.001 & 3.420 & 0.040 \\
\hline & Treatment & 1 & 240.339 & $<0.001$ & 7.660 & 0.008 & 95.881 & $<0.001$ \\
\hline & Treatment $\times$ Harvesting time & 2 & 90.807 & $<0.001$ & 28.145 & $<0.001$ & 38.953 & $<0.001$ \\
\hline \multirow[t]{3}{*}{ Fine root } & Harvesting time & 2 & 8.291 & 0.001 & 133.668 & $<0.001$ & 6.050 & 0.004 \\
\hline & Treatment & 1 & 195.636 & $<0.001$ & 1437.802 & $<0.001$ & 149.073 & $<0.001$ \\
\hline & Treatment $\times$ Harvesting time & 2 & 139.294 & $<0.001$ & 243.326 & $<0.001$ & 41.284 & $<0.001$ \\
\hline \multirow[t]{3}{*}{ Coarse root } & Harvesting time & 2 & 3.635 & 0.033 & 27.755 & $<0.001$ & 1.727 & 0.188 \\
\hline & Treatment & 1 & 0.184 & 0.670 & 209.412 & $<0.001$ & 31.763 & $<0.001$ \\
\hline & Treatment $\times$ Harvesting time & 2 & 6.221 & 0.004 & 38.830 & $<0.001$ & 10.505 & $<0.001$ \\
\hline
\end{tabular}




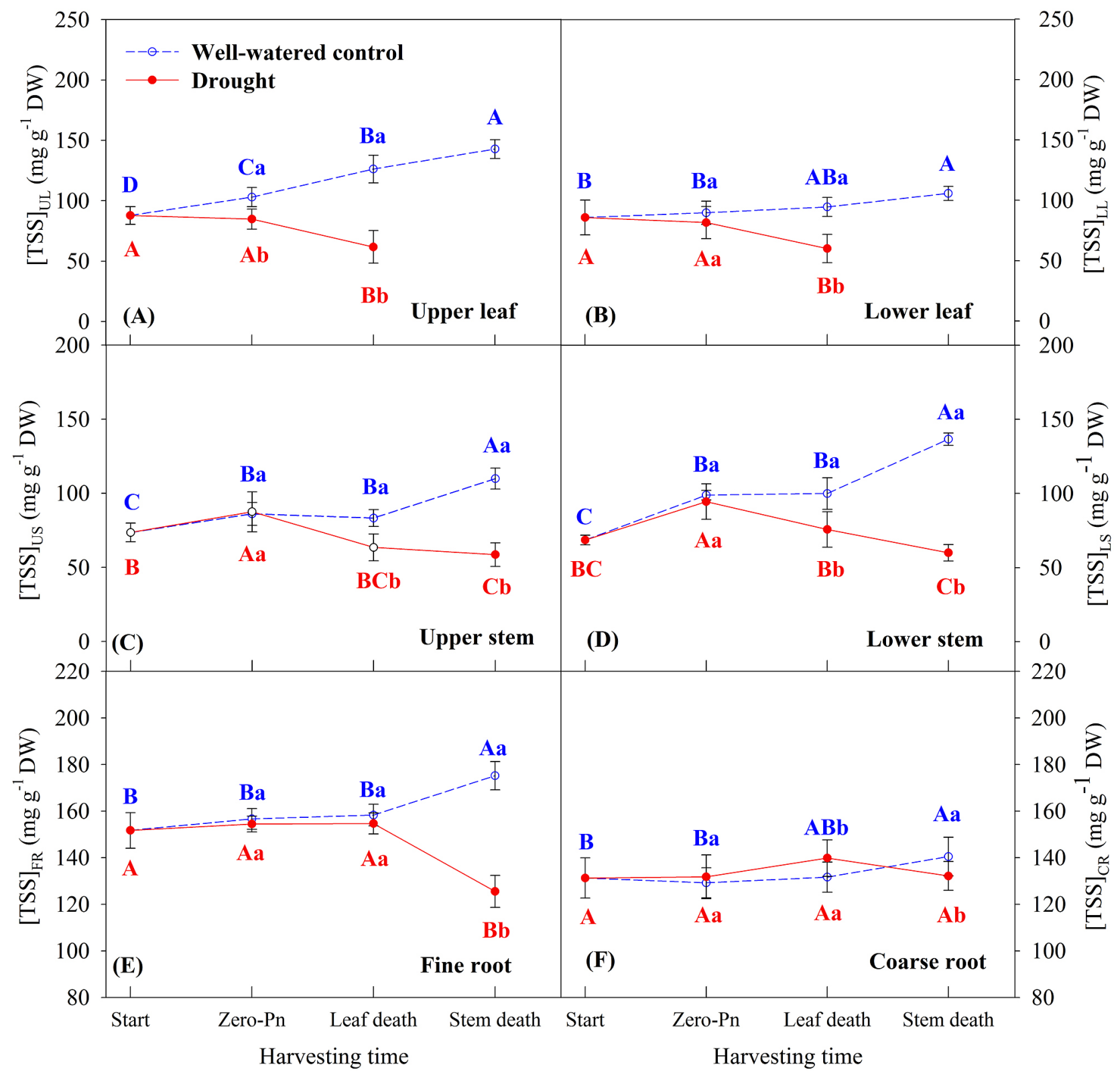

Fig. 2. Effects of the treatment (drought and well-watered control) on [TSS] in upper leaf ([TSS $\left.]_{\mathrm{UL}}\right)(\mathrm{A})$, lower leaf $\left([\mathrm{TSS}]_{\mathrm{LL}}\right)(\mathrm{B})$, upper stem $\left([\mathrm{TSS}]_{\mathrm{US}}\right)(\mathrm{C})$, lower stem $\left([\mathrm{TSS}]_{\mathrm{LS}}\right)(\mathrm{D})$, fine root $\left([\mathrm{TSS}]_{\mathrm{FR}}\right)(\mathrm{E})$, and coarse root $\left([\mathrm{TSS}]_{\mathrm{CR}}\right)$ (F) in $C$. bungei plants at different harvesting times. The values are the mean \pm standard deviation $(n=10)$. DW: dry matter weight. The different uppercase letters indicate significant differences in harvesting time for the same treatment $(P<0.05$; Tukey test), and the different lowercase letters indicate significant differences between treatments at the same harvesting time $(P<0.05$; Student's $t$-test); blue and red letters respectively present statistical results for well-watered control and drought

there were no significant differences in harvesting times for the upper leaf [TSS] and [NSC], lower leaf [Starch], upper stem [Starch], or coarse root [NSC]. In general, we observed significant interactions for the [TSS], [Starch], and [NSC] values of each organ between the harvesting time and treatment (Table 3 ), implying that the [TSS], [Starch], and [NSC] in each organ at different harvesting times responded differently to the treatments.

Under well-watered condition, the [TSS] in each organ gradually increased during the experiment
(Fig. 2). The dynamic change of [Starch] in CK plants differed among organs: in upper leaf and stem it showed a relatively narrow range; in lower leaf and stem it fluctuated dissimilarly; in roots (fine roots and coarse roots) it increased slowly (Fig. 3). The [NSC] in each organ of the CK plants generally showed an increasing tendency, demonstrating that NSC reserves accumulated in all organs of the well-watered plants (Fig. 4). The drought treatment provoked different changes in the [TSS], [Starch], and $[\mathrm{NSC}]$ among the organs and harvesting times 


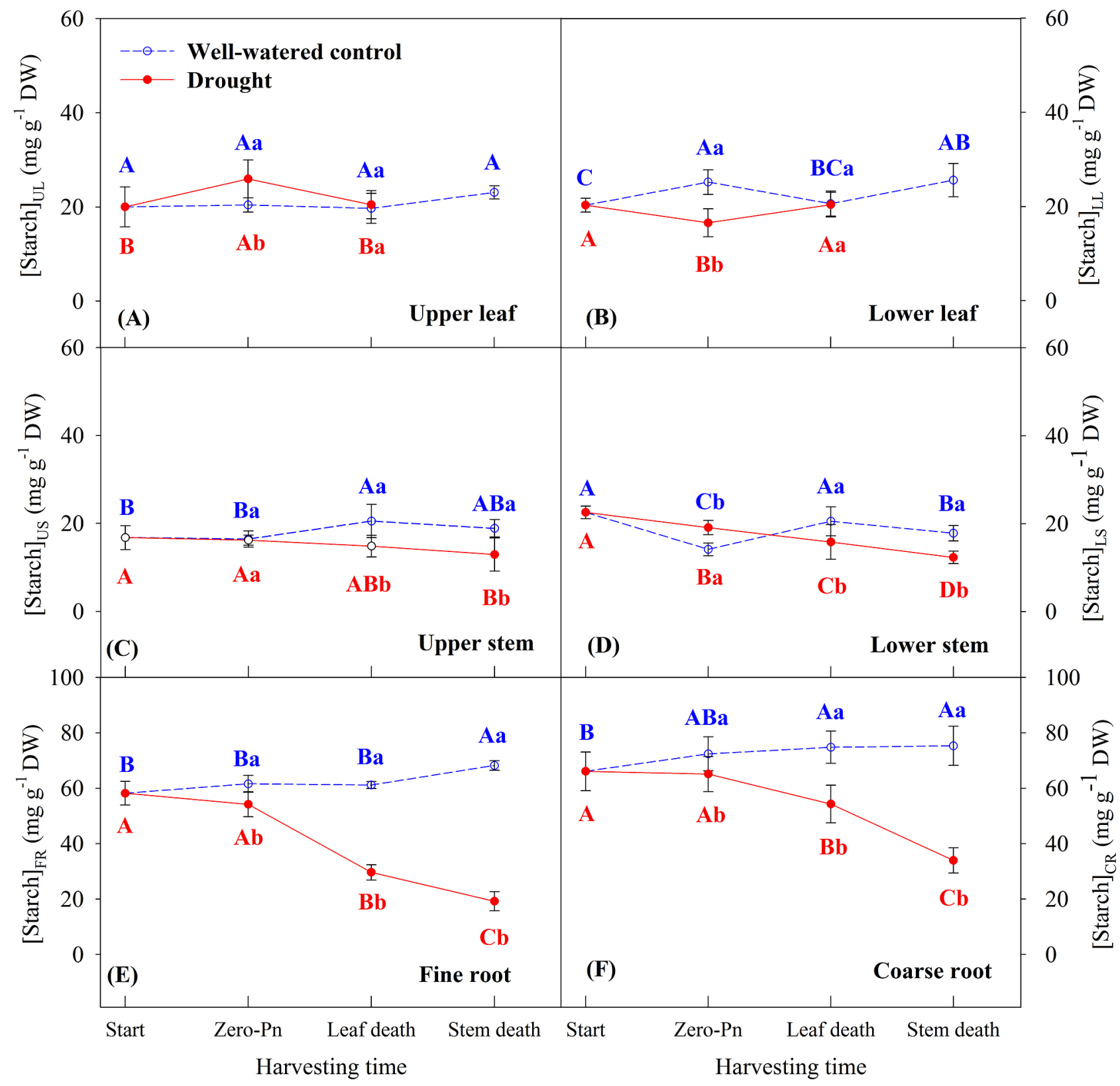

Fig. 3. Effects of the treatment (drought and well-watered control) on [Starch] in upper leaf ([Starch $\left.]_{\mathrm{UL}}\right)(\mathrm{A})$, lower leaf $\left([\text { Starch }]_{\mathrm{LL}}\right)(\mathrm{B})$, upper stem $\left([\text { Starch }]_{\mathrm{US}}\right)(\mathrm{C})$, lower stem $\left([\mathrm{Starch}]_{\mathrm{LS}}\right)(\mathrm{D})$, fine root $\left([\mathrm{Starch}]_{\mathrm{FR}}\right)(\mathrm{E})$, and coarse root $\left([\mathrm{Starch}]_{\mathrm{CR}}\right)(\mathrm{F})$ in C. bungei plants at different harvesting times. For explanation of symbols see legend to Fig. 2

(Fig. 2, 3, and 4). Zero-Pn plants had similar level of leaf [TSS] as the Start plants, but Leaf-death plants had significantly lower level (Fig. 2A and 2B). Stem (upper stem and lower stem) [TSS] firstly increased and then gradually declined during the drought period, and Stem-death plants had a significant lower level of stem [TSS] than Start plants (Fig. 2B and 2C). As drought progressed, fine root [TSS] remained invariable, coarse root [TSS] initially remained invariable (before Stem-death) and then decreased at Stemdeath (Fig. 2C and 2D). Compared to the Start plants, Zero-Pn plants had greater level of [Starch] in upper leaf $\left([\mathrm{Starch}]_{\mathrm{UL}}\right)$ and lower level of [Starch] in lower leaf $\left([\text { Starch }]_{L L}\right)$, but Leaf-death had similar level of $[\text { Starch }]_{\mathrm{LL}}$ and $[\text { Starch }]_{\mathrm{UL}}$ (Fig. 3A and 3B). Stem and root [Starch] gradually decreased during drought (Fig. 3C, 3D, 3E, and 3F). Compared to the Start plants, Zero-Pn plants had similar levels of [NSC] uL and $[\mathrm{NSC}]_{\mathrm{LL}}$, whereas Leaf-death plants showed a significant loss in $[\mathrm{NSC}]_{\mathrm{UL}}$ and $[\mathrm{NSC}]_{\mathrm{LL}}$ (Fig. $2 \mathrm{~A}$ and 2B). Meanwhile, Zero-Pn plants had higher [NSC] us and $[\mathrm{NSC}]_{\mathrm{LS}}$ than did Start plants, demonstrating that the $[\mathrm{NSC}]$ increased in the stems of plants before photosynthesis ceased, whereas Leaf-death and Stem-death plants had significantly lower concentrations than did Start plants (Fig. 2C and 2D). In addition, Zero-Pn plants had similar $[\mathrm{NSC}]_{\mathrm{FR}}$ to Start plants, but Leaf-death and Stem-death plants had 


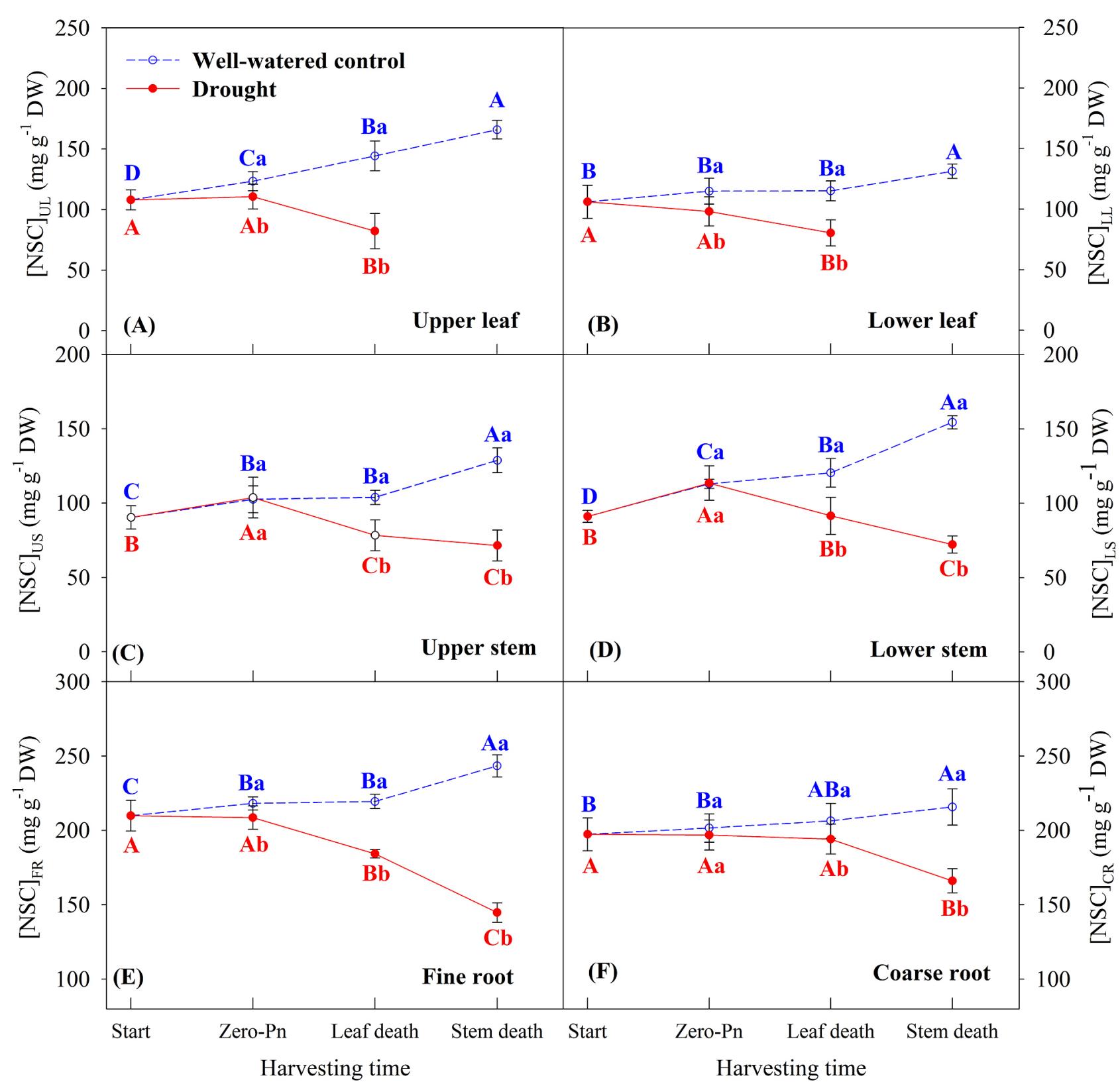

Fig. 4. Effects of the treatment (drought and well-watered control) on $[\mathrm{NSC}]$ in upper leaf $\left([\mathrm{NSC}]_{\mathrm{UL}}\right)(\mathrm{A})$, lower leaf $\left([\mathrm{NSC}]_{\mathrm{LL}}\right)(\mathrm{B})$, upper stem $\left([\mathrm{NSC}]_{\mathrm{US}}\right)(\mathrm{C})$, lower stem $\left([\mathrm{NSC}]_{\mathrm{LS}}\right)(\mathrm{D})$, fine root $\left([\mathrm{NSC}]_{\mathrm{FR}}\right)(\mathrm{E})$, and coarse root ([NSC] $\left.{ }_{\mathrm{CR}}\right)(\mathrm{F})$ in C. bungei plants at different harvesting times. For explanation of symbols see legend to Fig. 2

lower levels (Fig. 2E). The $[\mathrm{NSC}]_{\mathrm{CR}}$ in both Zero-Pn and Leaf-death plants showed no significant differences relative to Start plants, but a significant loss in $[\mathrm{NSC}]_{\mathrm{CR}}$ was detected in Stem-death plants (Fig. 2F).

Overall, the difference in [TSS], [Starch], and [NSC] between the treatments (D versus CK) at the same harvesting time all differed among the organs. At Zero-Pn, organ [TSS] showed no significant difference between treatments (Fig. 2). At Leaf-death plants had lower [TSS] than CK1 in all the organs than CK1, with the exception of fine roots, which had similar level of [TSS]. At Stem-death plants had lower [TSS] in all the organs than CK2 (Fig. 2). Compared to CK1, Zero-Pn plants had greater [Starch] in upper leaf $\left([\text { Starch }]_{\mathrm{UL}}\right)$ and lower stem $\left([\text { Starch }]_{\mathrm{LS}}\right)$, lower $[$ Starch $]$ in lower leaf $\left([\text { Starch }]_{\mathrm{LL}}\right)$ and roots, and similar level of [Starch] in upper stem ([Starch $]_{\mathrm{US}}$ ) (Fig. 3). Compared to CK2, Leaf-death plants had lower [Starch] values in roots and stems, but had similar level of ([Starch $]_{\mathrm{UL}}$ and $[\text { Starch }]_{\mathrm{LL}}$ (Fig. 3). The [Starch] in all the organs at Stem-death were significantly lower than those of the CK3 plants. The [NSC] in upper leaf $\left([\mathrm{NSC}]_{\mathrm{UL}}\right)$, lower leaf $\left([\mathrm{NSC}]_{\mathrm{LL}}\right)$, and fine root ([NSC] $\left.{ }_{F R}\right)$ of Zero-Pn plants were significantly lower than those of CK1 plants (Fig. 2A, 2B, and 2E), whereas no significant differences in $[\mathrm{NSC}]_{\mathrm{US}},[\mathrm{NSC}]_{\mathrm{LS}}$, and $[\mathrm{NSC}]_{\mathrm{CR}}$ between Zero-Pn and CK1 plants were detected (Fig. 2C, 2D, and 2F). Moreover, the [NSC] 


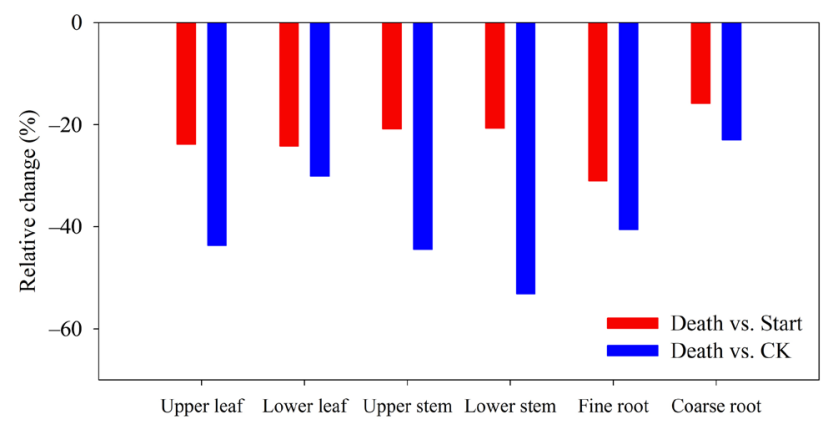

Organ

Fig. 5. Relative changes (\%) in the non-structural carbohydrate concentrations in the organs of Catalpa bungei plants at death (Leaf-death and Stem-death) over those at Start or in the respective controls (Leaf-death vs. CK1; Stem-death vs. CK2)

values of all organs of the Leaf-death and Stem-death plants were significantly lower than those of the CK2 and CK3 plants, respectively (Fig. 2). There was overwhelming evidence that the organs at death retained some NSC reserves (71.52-166.10 $\mathrm{mg} \mathrm{g}^{-1} \mathrm{DW}$ ) (Fig. 4), although they showed $15.84 \sim 31.04 \%$ loss of [NSC] relative to Start plants, and had [NSC] reductions of $23.02 \sim 53.19 \%$ compared to CK plants (Fig. $5)$. The [NSC] in organs at death was decreased by $15.84 \sim 31.04 \%$ and $23.02 \sim 53.19 \%$ compared to Start and CK plants, respectively (Fig. 5), but still retained 71.52-166.10 $\mathrm{mg} \mathrm{g}^{-1}$ DW (Fig. 4).

\section{Discussion}

NSC reserves in temperate deciduous tree species generally increase gradually during the growing season to create sufficient NSCs for overwintering (Kozlowski, 1992). Our results were in agreement with this trend in that well-watered plants accumulated NSC reserves in all organs during experiment (This study ended at the end of growing season in north-western China; Fig. 2). Consistent with the need to quantify the [NSC] in dead or dying plants (Piper et al., 2009; McDowell et al., 2010; McDowell, 2011), our results emphasised the importance of observing NSC dynamics in plants that have succumbed to drought. Drought-tolerant trees often cope with drought through improving osmotic adjustments, characterized by increasing soluble sugars (Maguire \& Kobe, 2015). We also observed that plants reduced starch and increased sugars for osmotic adjustments to tolerate drought, especially in the early period of drought (Fig. 2 and 3). However, starch deficiency occurred in roots and lower stems under extreme drought (Fig. 3), resulting in sugars decline in all the organs due to the absence of the conversion of stored starch (Fig. 2), suggesting that plant death during prolonged drought was related to the failure in osmotic adjustment. Moreover, our results were consistent with those of a predictive simulation that showed an NSC surplus during early drought, although the [NSC] began to decline when photosynthesis was significantly reduced due to drought (McDowell, 2011). In the present study, during drought, plants at death exhibited a loss in [NSC] in all organs compared with Start or corresponding CK (CK2 or CK3) plants, indicating that a loss of stored NSC occurred in plants succumbing to drought and that the lost NSCs were mainly consumed to improve tolerance of drought stress. Meanwhile, Zero-Pn plants generally had NSC reserves similar to, or greater than, those of Start or CK1 plants (Fig. 2). One possible explanation is that NSC loss leading to death ensued when photosynthesis had ceased (McDowell, 2011). Isohydric C. bungei tolerate drought by avoidance strategy: maintaining a constant midday leaf water potential under drought conditions, by reducing stomatal conductance as necessary to limit transpiration (Dong et al., 2013; Zheng et al., 2017). Photosynthesis ceases in plants suffering from severe drought due to stomatal limitation (Piper, 2011; Yang et al., 2014; Xu et al., 2015), which we observed in the present study (Fig. 1). Thus, the main supply of NSCs is cut off when photosynthesis ceases, and the plant must consume stored NSCs to maintain its metabolism and defence mechanisms (McDowell, 2011). Due to NSC loss, carbon starvation occurs when carbon acquisition and storage do not meet the needs of maintaining metabolism, increasing the risk of plant death (Sala et al., 2010).

The NSC allocation strategies, carbon translocation, or metabolic necessities among different plant organs can be comprehensively influenced by biological and environmental factors, and are generally correlated closely with long-term survival and ecological adaptation strategies (Barbaroux et al., 2003; Litton et al., 2004; Rachmilevitch et al., 2006; Millard et al., 2007; Sala et al., 2010). Our results showed that leaves were shed earlier compared to stem death, consistent with the hypothesis of hydraulic segmentation. Accordingly, the loss of the more vulnerable leaves help to avoid hydraulic failure extending to the stems that have higher construction costs (Bucci et al., 2012). Unlike roots or leaves, stems at zero-Pn had similar level of [NSC] as CK1 stems (Fig 4C and 4D), suggesting that light drought did not affect stem [NSC]. This finding might be attributed to the potential effects of drought on NSC translocation, as stated by Sala et al. (2010). Under drought, much of stored and newly assimilated NSCs might have been translocated into stems for phloem turgor maintenance to drive phloem transport. Previous studies suggest that carbohydrate storage enhances plant stress tolerance and survival (Myers \& Kitajima, 2007; O’Brien et al., 2014). 
During prolonged drought, upper leaves (20 d) had relative longer survival time than lower leaves (15 d) (Fig. 1). The possible reason was that upper leaves could maintain higher NSC levels reflecting their longer photosynthetic activity. Also, lower stems $(34 \mathrm{~d})$ survived drought for longer time than upper stems (26 d) (Fig. 1), and their survival time was related to the occurrence time of their NSC loss, i.e., upper stems showed NSC loss earlier than lower stems (Fig. 4). Fine roots are mainly used for water and nutrient absorption (Lei et al., 2012; Cui et al., 2017), whereas the main functions of coarse roots include the transport and storage of various nutrients and metabolites such as NSCs (Bengough et al., 2011; Cui et al., 2017). Our results showed that fine roots showed earlier NSC loss than did coarse roots (Fig. 4E and 4F), which might be explained by their different functions (Cui et al., 2017). Under severe drought, coarse roots could initially maintain their [NSC] due to supply from their stored NSC, but fine roots showed NSC loss earlier due to a lack of NSC storage and greater carbon demands, suggesting that mortality of fine roots are expected to down-regulate carbon demands under water stress (Sala et al., 2010). Notably, we found evidence that the [NSC] dynamics, occurrence time of carbon starvation, and survival time varied among the organs, and even within the same organ type at different position on the stem.

As described by various researchers, trees can die due both to hydraulic failure and to carbon starvation (Hartmann et al., 2013; Hereş et al., 2014; Sevanto et al., 2014). Because the role of hydraulic failure in determining drought-induced plant mortality has been adequately documented in a growing number of empirical studies, the hydraulic failure hypothesis is now widely accepted (Vilagrosa et al., 2003; Hartmann et al., 2013; Sevanto et al., 2014; Pellizzari et al., 2016; Adams et al., 2017). Several previous studies on deciduous broad-leaved tree species are inconsistent with the $\mathrm{CSH}$, for example, Anderegg et al. (2012) found substantial evidence of hydraulic failure of roots and branches linked to canopy and root mortality in Populus tremuloides, but found no evidence that drought results in the depletion of carbohydrate reserves. Also, Piper and Fajardo (2016) suggested that growth reductions in Acer pseudoplatanus seedlings subjected to drought for 3 months are not accompanied by carbohydrate storage reductions. However, our results are compatible with the $\mathrm{CSH}$, supporting the view that carbon starvation is not universal, and these conflicting findings might be explained by the difference in xylem hydraulic vulnerability among species (Adams et al., 2017). As hypothesized by Mitchell et al. (2014) and Mencuccini et al. (2015), drought sensitive C. bungei plantlets with low resistance to xylem embolism that close their stomata earlier during drought are prone to show a reduction in NSC associated with carbon starvation. Hence, more experimental tests of carbon starvation in deciduous broad-leaved tree species, in addition to evergreen or coniferous trees should be conducted to provide a necessary basis to better understand plant mortality mechanisms. Overall, we tend to agree with the view that carbohydrate metabolism and utilization strategies (e.g., storage, sequestration, translocation, etc.) have an important role in determining plant survival, in addition to hydraulic parameters (Vilagrosa et al., 2003; Sala et al., 2010; Sevanto et al., 2014). From this perspective, the quantification of NSC dynamics in plants during drought stress is a good starting point to test the CSH (McDowell, 2011).

Considering the shortage of evidence, the main concerns in understanding the mechanisms of carbon starvation are the determination of whether, and if so how, when, and where, carbon starvation occurs (McDowell \& Sevanto, 2010). We observed that carbon starvation occurs in roots, stems, and leaves concurring with plantlets death during drought. Although we did not determine the specific timing of carbon starvation occurrence, our results preliminarily show that carbon starvation occurs after photosynthesis ceases, providing evidence to help clarify the mechanisms of carbon starvation.

Predicting the survival time of trees is difficult due to a lack of available tests to understand the mechanism of mortality. Among recent studies, Sevanto et al. (2014) stated that hydraulic constraints on plant carbohydrate use determined the survival time, and Doughty et al. (2015) observed that tree survival time was determined by the carbon utilisation strategy during drought (i.e., priorities of carbohydrate allocation: growth or metabolism and defence). Moreover, our results revealed that dead plants had [NSC] values greater than zero in all organs, further demonstrating that plants maintain some NSC reserves to survive drought. This finding might be explained by the hypothesis of carbon sequestration postulating that much of NSC are sequestered in woody tissues and not reusable (Millard et al., 2007). However, we did not determine the threshold [NSC] for carbon starvation in the plants, which is an important topic for future research.

\section{Conclusion}

This study presents an assessment of carbon starvation during the process of drought-induced death in deciduous broad-leaved C. bungei plants. The results indicated that drought led to NSC loss in all the organs at death, that carbon starvation appeared to begin after photosynthesis has ceased, and that 
dead plants retained some NSC reserves. The [NSC] dynamics, occurrence time of carbon starvation, and survival time varied among organs. Furthermore, leaves and stems at different stem heights exhibited asynchronous survival times. Overall, our results showing that the depletion of carbohydrate reserves occurs in all the organs of plants undergoing drought-induced mortality are compatible with $\mathrm{CSH}$ . Our findings have some limitations based on the study materials used and methods and the use of experimentally controlled drought rather than natural drought conditions. The interaction between hydraulic failure and carbon starvation should be factored into future studies of the mechanisms of plant death. Experiments should be designed to test the carbon starvation and hydraulic failure hypotheses and determine critical [NSC] values to verify the mechanism of plant death.

\section{Acknowledgements}

This work was supported by the National Key R\&D Program of China (2017YFD0600604; 2017YFD060060404).

\section{References}

Adams HD, Zeppel MJB, Anderegg WRL, Hartmann $H$, Landhäusser SM, Tissue DT, Huxman TE, Hudson PJ, Franz TE, Allen CD, Anderegg LDL, Barron-Gafford GA, Beerling DJ, Breshears DD, Brodribb TJ, Bugmann H, Cobb RC, Collins AD, Dickman LT, Duan H, Ewers BE, Galiano L, Galvez DA, Garcia-Forner N, Gaylord ML, Germino MJ, Gessler A, Hacke UG, Hakamada R, Hector A, Jenkins MW, Kane JM, Kolb TE, Law DJ, Lewis JD, Limousin JM, Love DM, Macalady AK, MartinezOVilalta J, Mencuccini M, Mitchell PJ, Muss JD, O’Brien MJ, O'Grady AP, Pangle RE, Pinkard EA, Piper FI, Plaut JA, Pockman WT, Quirk J, Reinhardt K, Ripullone F, Ryan MG, Sala A, Savanto S, Sperry JS, Vargas R, Vennetier M, Way DA, Xu C, Yepez EA \& McDowell NG (2017) A multi-species synthesis of physiological mechanisms in drought-induced tree mortality. Nature Ecology \& Evolution 1: 1285-1291. doi:10.1038/s41559017-0248-x.

Adams HD, Guardiola-Claramonte M, Barron-Gafford GA, Villegas JC, Breshears DD, Zou CB, Torch PA \& Huxman TE (2009) Temperature sensitivity of drought-induced tree mortality portends increased regional die-off under global-changetype drought. Proceedings of the National Academy of Sciences 106: 7063-7066. doi:10.1073/ pnas.0901438106.
Allen CD, Macalady A, Chenchouni H, Bachelet D, McDowell N,Vennetier M, Gonzales P, Hogg T, Rigling A, Breshears DD, Hogg EH, Gonzalez P, Fensham R, Zhang Z, Castro J, Demidova N, Lim JH, Allard G, Running SW, Semerci A \& Cobb N (2010) A global overview of drought and heat-induced tree mortality reveals emerging climate change risks for forests. Forest Ecology and Management 259: 660-684. doi:10.1016/j.foreco.2009.09.001.

Anderegg WRL, Berry JA, Smith DD, Sperry JS, Anderegg LDL \& Field CB (2012) The roles of hydraulic and carbon stress in a widespread climate-induced forest die-off. Proceedings of the National Academy of Sciences 109: 233-237. doi:10.1073/ pnas.1107891109.

Barbaroux C, Bréda N \& Dufrêne E (2003) Distribution of above-ground and below-ground carbohydrate reserves in adult trees of two contrasting broad-leaved species (Quercus petraea and Fagus sylvatica). New Phytologist 157: 605-615. doi:10.1046/j.1469-8137.2003.00681.x.

Bengough AG, McKenzie BM, Hallett PD \& Valentine TA (2011) Root elongation, water stress, and mechanical impedance: a review of limiting stresses and beneficial root tip traits. Journal of Experimental Botany 62: 59-68. doi:10.1093/jxb/ erq350.

Bréda N, Huc R, Granier A \& Dreyer E (2006) Temperate forest trees and stands under severe drought: a review of ecophysiological responses, adaptation processes and long-term consequences. Annals of Forest Science 63: 625-644. doi:10.1051/forest:2006042.

Bucci SJ, Scholz FG, Campanello PI, Montti L, Jimenez-Castillo M, Rockwell FA, Manna LL, Guerra P, Bernal PL, Troncoso O, Enricci J, Holbrook MN \& Goldstein G (2012) Hydraulic differences along the water transport system of South American nothofagus species: do leaves protect the stem functionality? Tree Physiology 32: 880-893. doi:10.1093/treephys/tps054.

Cui Q, Feng Z \& Yang X (2017) Distributions of fine and coarse tree roots in a semi-arid mountain region and their relationships with soil properties. Trees - Structure \& Function 31: 607-616. doi:10.1007/s00468-016-1493-3.

Dong L, Li JY, Wang JH, Xie K \& Su Y (2014) Effects of drought stress on osmotic regulation substances of five Catalpa bungei clones. Agricultural Science \& Technology 14: 1335-1343.

Doughty CE, Metcalfe DB, Girardin CAJ, Amézquita FF, Cabrera DG, Huasco WH, Silva-Espejo JE, Araujo-Murakami A, da Costa MC, Rocha W, Feldpausch TR, Mendoza ALM, da Costa AC, Meir P, Phillips OL \& Malhi Y (2015) Drought impact on 
forest carbon dynamics and fluxes in Amazonia. Nature 519: 78-82. doi:10.1038/nature14213.

Gruber A, Pirkebner, Florian C \& Oberhuber W (2012) No evidence for depletion of carbohydrate pools in Scots pine (Pinus sylvestris L.) under drought stress. Plant Biology 14: 142-148. doi:10.1111/j.1438-8677.2011.00467.x.

Hartmann H, Ziegler W, Kolle O \& Trumbore S (2013) Thirst beats hunger-declining hydration during drought prevents carbon starvation in Norway spruce saplings. New Phytologist 200: 340-349. doi:10.1111/nph.12331.

Hereş AM, Camarero JJ, López BC \& Martínez-Vilalta J (2014) Declining hydraulic performances and low carbon investments in tree rings predate Scots pine drought-induced mortality. Trees - Structure \& Function 28: 1737-1750. doi:10.1007/s00468014-1081-3.

Kozlowski TT (1992) Carbohydrate sources and sinks in woody plants. The Botanical Review 58: 107-222. doi:10.1007/bf02858600.

Lei P, Scherer-Lorenzen M \& Bauhus J (2012) Belowground facilitation and competition in young tree species mixtures. Forest Ecology and Management 265: 191-200. doi:10.1016/j.foreco.2011.10.033.

Liang E, Shao X, Kong Z \& Lin J (2003) The extreme drought in the 1920s and its effect on tree growth deduced from tree ring analysis: a case study in North China. Annals of Forest Science 60: 145152. doi:10.1051/forest:2003007.

Litton CM, Ryan MG \& Knight DH (2004) Effects of tree density and stand age on carbon allocation patterns in postfire lodgepole pine. Ecological Applications 14: 460-475. doi:10.1890/02-5291.

Lu RK (1999) Analytical methods of soil agricultural chemistry. China Agricultural Science and Technology Press, Beijing, pp. 12-18, 106, 146-194.

Maguire AJ \& Kobe RK (2015) Drought and shade deplete nonstructural carbohydrate reserves in seedlings of five temperate tree species. Ecology \& Evolution 5: 5711-5721. doi:10.1002/ece3.1819.

McDowell N, Pockman WT, Allen CD, Breshears DD, Cobb N, Kolb T, Plaut J, Sperry J, West A, Williams DG \& Yepez EA (2008) Mechanisms of plant survival and mortality during drought: why do some plants survive while others succumb to drought? New Phytologist 178: 719-739. doi:10.1111/ j.1469-8137.2008.02436.x.

McDowell NG \& Sevanto S (2010) The mechanisms of carbon starvation: how, when, or does it even occur at all? New Phytologist 186: 264-266. doi:10.1111/j.1469-8137.2010.03232.x.

McDowell NG (2011) Mechanisms linking drought, hydraulics, carbon metabolism, and vegetation mortality. Plant Physiology 155: 1051-1059. doi:10.1104/pp.110.170704.
McDowell NG, Allen CG \& Marshall L (2010) Growth, carbon isotope discrimination, and drought-associated mortality across a Pinus ponderosa elevation transect. Global Change Biology 16: 399-415. doi:10.1111/j.1365-2486.2009.01994.x.

Mencuccini M, Minunno F, Salmon Y, Martinez-Vilalta J \& Holtta T (2015) Coordination of physiological traits involved in drought-induced mortality of woody plants. New Phytologist 208: 396-409. doi:10.1111/nph.13461.

Millard P, Sommerkorn M \& Grelet GA (2007) Environmental change and carbon limitation in trees: a biochemical, ecophysiological and ecosystem appraisal. New Phytologist 175: 11-28. doi:10.1111/j.1469-8137.2007.02079.x.

Mitchell PJ, O'Grady AP, Tissue DT, Worledge D \& Pinkard EA (2014) Co-ordination of growth, gas exchange and hydraulics define the carbon safety margin in tree species with contrasting drought strategies. Tree Physiology 34: 443-458. doi:10.1093/treephys/tpu014.

Myers JA \& Kitajima K (2007) Carbohydrate storage enhances seedling shade and stress tolerance in a neotropical forest. Journal of Ecology 95: 383395. doi:10.1111/j.1365-2745.2006.01207.x.

Niu SL, Luo YQ, Li DJ, Cao SH, Xia JY, Li JW \& Smith MD (2014) Plant growth and mortality under climatic extremes: An overview. Environmental and Experimental Botany 98: 13-19. doi:10.1016/j. envexpbot.2013.10.004.

O'Brien MJ, Leuzinger S, Philipson CD, Tay J \& Hector A (2014) Drought survival of tropical tree seedlings enhanced by non-structural carbohydrate levels. Nature Climate Change 4: 710-714. doi:10.1038/nclimate2281.

O'Grady AP, Mitchell PJ, Pinkard EA \& Tissue DT (2013) Thirsty roots and hungry leaves: unravelling the roles of carbon and water dynamics in tree mortality. New Phytologist 200: 294-297. doi:10.1111/nph.12451.

Paddock WS, Davis SD, Pratt RB, Jacobsen AL, Tobin MF, Lopez-Portillo J \& Ewers FW (2013) Factors determining mortality of adult chaparral shrubs in an extreme drought year in California. Aliso 31: 49-57. doi:10.5642/aliso.20133101.08.

Pellizzari E, Camarero JJ, Gazol A, Sangüesa-Barreda G \& Carrer M (2016) Wood anatomy and carbon-isotope discrimination support longterm hydraulic deterioration as a major cause of drought-induced dieback. Global Change Biology 22: 2125-2137. doi:10.1111/gcb.13227.

Peterson CA (1979) Selective vital staining of companion cells of potato tuber and parsnip root with neutral red. Stain Technology 54: 135-139. doi:10.3109/10520297909112648.

Piper FI \& Fajardo A (2016) Carbon dynamics of Acer pseudoplatanus seedlings under drought and com- 
plete darkness. Tree Physiology 36: 1400-1408. doi:10.1093/treephys/tpw063.

Piper FI (2011) Drought induces opposite changes in the concentration of non-structural carbohydrates of two evergreen Nothofagus species of differential drought resistance. Annals of Forest Science 68: 415-424.

Piper FI, Reyes-Diáz EM, Corcuera LJ \& Lusk CH (2009) Carbohydrate storage, survival, and growth of two evergreen Nothofagus species in two contrasting light environments. Ecological Research 24: 1233-1241. doi:10.1007/s11284009-0606-5.

Rachmilevitch S, Huang BR \& Lambers H (2006) Assimilation and allocation of carbon and nitrogen of thermal and nonthermal Agrostis species in response to high soil temperature. New Phytologist 170: 479-490. doi:10.1111/j.14698137.2006.01684.x.

Rebetez M \& Dobbertin M (2004) Climate change may already threaten Scots pine stands in the Swiss Alps. Theoretical and Applied Climatology 79: 1-9. doi:10.1007/s00704-004-0058-3.

Rowland L, da Costa ACL, Galbraith DR, Oliveira RS, Binks OJ, Oliveira AAR, Pullen AM, Doughty CE, Metcalfe DB, Vasconcelos SS, Ferreira LV, Malhi Y, Grace J, Mencuccini M \& Meir P (2015) Death from drought in tropical forests is triggered by hydraulics not carbon starvation. Nature 528 : 119-122. doi:10.1038/nature15539.

Sala A, Piper F \& Hoch G (2010) Physiological mechanisms of drought-induced tree mortality are far from being resolved. New Phytologist 186: 274 281. doi:10.1111/j.1469-8137.2009.03167.x.

Salmon Y, Torres-Ruiz J M, Poyatos R, Martinez-Vilalta J, Meir P, Cochard H \& Mencuccini M (2015) Balancing the risks of hydraulic failure and carbon starvation: A twig scale analysis in declining Scots pine. Plant, Cell \& Environment 38: 2575-2588. doi:10.1111/pce.12572.

Sevanto S, McDowell NG, Dickman LT, Pangle R \& Pockman WT (2014) How do trees die? A test of the hydraulic failure and carbon starvation hypotheses. Plant, Cell \& Environment 37: 153161. doi:10.1111/pce.12141.

van Mantgem PJ, Stephenson NL, Byrne JC, Daniels LD, Franklin JF, Fule PZ, Harmon ME, Lar- son AJ, Smith JM, Taylor AH \& Veblen TT (2009) Widespread increase of tree mortality rates in the Western United States. Science 323: 521-524. doi:10.1126/science.1165000.

Vilagrosa A, Bellot, Vallejo VR \& Gil-Pelegrín E (2003) Cavitation, stomatal conductance, and leaf dieback in seedlings of two co-occurring Mediterranean shrubs during an intense drought. Journal of Experimental Botany 54: 2015-2024. doi:10.1093/jxb/erg221.

Wang L, Dai YX, Guo JP, Gao RM \& Wan CX (2016) Interaction of hydraulic failure and carbon starvation on Robinia pseudoacacia seedlings during drought. Scientia Silvae Sinicae 52: 1-9. doi:10.11 707/j.1001-7488.20160601.

Ward JK, Harris JM, Cerling TE, Wiedenhoeft A, Lott MJ, Dearing MD, Coltrain JB \& Ehleringer JR (2005) Carbon starvation in glacial trees recovered from the La Brea tar pits, southern California. Proceedings of the National Academy of Sciences 102: 690-694. doi:10.3410/f.1024284.286795.

Xu NN, Wang RQ, Liu J, Lu PL \& Guo WH (2015) Hierarchy of plasticity traits in responses of Quercus aliena to light conditions and water availability. Dendrobiology 74: 169-180. doi:10.12657/ denbio.074.017.

Yang PM, Huang QC, Qin GY, Zhao SP \& Zhou JG (2014) Different drought-stress responses in photosynthesis and reactive oxygen metabolism between autotetraploid and diploid rice. Photosynthetica 52: 193-202. doi:10.1007/s11099014-0020-2.

Zhang XQ, Lei YC, Pang Y, Liu XZ \& Wang JZ (2014) Tree mortality in response to climate change induced drought across Beijing, China. Climatic Change 124: 179-190. doi:10.1007/s10584-0141089-0.

Zheng HF, Zhang X, Ma WJ, Song J, Rahman SU, Wang JH \& Zhang Y (2017) Morphological and physiological responses to cyclic drought in two contrasting genotypes of Catalpa bungei. Environmental \& Experimental Botany 138: 77-87. doi:10.1016/j.envexpbot.2017.02.016.

Zou Q (1995) Guidance of plant physiological and biochemical experiments. China Agriculture Press, Beijing, pp. 53-55. 